June 2017

\title{
Linguistics and LIS: A Research Agenda
}

Mary K. Bolin

University of Nebraska--Lincoln, mbolin2@unl.edu

Follow this and additional works at: https://scholarworks.sjsu.edu/ischoolsrj

Part of the Library and Information Science Commons

\section{Recommended Citation}

Bolin, M. K. (2017). Linguistics and LIS: A Research Agenda. School of Information Student Research Journal, 7(1). https://doi.org/10.31979/2575-2499.070102 Retrieved from https://scholarworks.sjsu.edu/ ischoolsrj/vol7/iss $1 / 2$

This article is brought to you by the open access Journals at SJSU ScholarWorks. It has been accepted for inclusion in School of Information Student Research Journal by an authorized administrator of SJSU ScholarWorks. For more information, please contact scholarworks@sjsu.edu. 


\title{
Linguistics and LIS: A Research Agenda
}

\begin{abstract}
Linguistics and Library and Information Science (LIS) are both interdisciplinary fields that draws from areas such as languages, psychology, sociology, cognitive science, computer science, anthropology, education, and management. The theories and methods of linguistic research can have significant explanatory power for LIS. This article presents a research agenda for LIS that proposes the use of linguistic analysis methods, including discourse analysis, typology, and genre theory.
\end{abstract}

\section{Keywords}

linguistics, library and information science research, discourse analysis, genre theory, systemic-functional linguistics

\section{About Author}

Mary K. Bolin, PhD, is Professor and Catalog and Metadata Librarian at the University of Nebraska-Lincoln, as well as a Lecturer in the School of Information at San Jose State University. She is one of the founding editors of the open access, peer-reviewed e-journal Library Philosophy and Practice. 
Linguistics is an interdisciplinary field that draws from study of languages, including English, and fields such as psychology, sociology, cognitive science, computer science, and anthropology. Library and Information Science (LIS) is also interdisciplinary, and can be studied using techniques from the humanities, social science, and science. The many theories and methods of linguistic research can be extremely useful and have significant explanatory power for LIS. This article presents a research agenda for LIS that proposes the use of linguistic analysis methods.

The elements of language are phonology, morphology, syntax, and semantics. The study of linguistics includes those areas, but also includes discourse analysis, linguistics universals and typology, sociolinguistics, psycholinguistics, language and cognition, language acquisition (including child language and second language acquisition), and many other topics and approaches. Language is a semiotic system, a system of signs. Halliday (1978) calls language a social semiotic. Written and spoken language are systems of signs that are used and understood by speakers. Languages and variants of languages are used in speech communities (e.g., speakers of Parisian French) and discourse communities (e.g., librarians) for purposes that include those of business and commerce, education, government, medicine, law, and every kind of human social and cultural event and occasion. We talk to each other, we read and write, and we carry out daily endeavors and longterm goals using language. As librarians, we already recognize the significance of the language that we use, in controlled vocabularies, in OPAC displays, in library signage and marketing, and in planning and problem-solving. As researchers, we can use the techniques of linguistic analysis to further unpack those plans and problems, and discover new theories and frameworks for helping library patrons discover and use information.

There is substantial and groundbreaking work being done in areas of library and information science such as search engine optimization, semantic web, natural language processing, and linked data. Those subjects are certainly linguistically oriented and often draw on the techniques of linguistic analysis, but this article does not focus on that area of the LIS and related literature. It provides information on frameworks, theories, and methods used in linguistics as they might be applied to many areas of LIS.

\section{Typology}

Typologies are used by many fields, but they are widely used in linguistic research, often as part of the search for linguistic universals: features or elements that are common to all, most, or many languages, and the contrast between the most and least common types in an area. Typology is used in research on semantic areas like kinship, color terms, and other culturally-salient phenomena, as well as syntax (the most and least common order of grammatical constituents in different languages). For example, the default order of constituents in English is subject-verb-object (SVO). SVO is one of the most common word order types, while OVS is the least common ("Word Order," n.d.). Comrie (1989), Croft (1990), Greenberg (2005), and other scholars have compared the characteristics of different languages to identify universal phenomena. Prototype semantics can also be used to create typologies (Lakoff, 1986; Rosch, 1973, 1977). In prototype theory, there are 
semantic categories with central and peripheral members. Members of a speech or discourse community may not agree on the boundaries of a category, but there is agreement about the center of the category or about its best representative, for example, a sparrow is a more typical bird than a penguin. Typology can be used in LIS research for studying things like librarian faculty status (Bolin 2007, 2008a, 2008b), library organizational patterns (Bolin, forthcoming 2017), and many other areas of library programs and services. It requires gathering data to answer a research question and then answering the question by dividing the data into types. The types are created using clusters of characteristics; for example, Bolin (2007) gathered data about librarian status at US land grant universities, and used characteristics such as eligibility for tenure, librarian rank system, and other things to create a typology of librarian status that including three faculty types and one staff type. There could be many other applications of linguistic typology to LIS. Those include:

- Models of liaison librarianship in academic libraries considering assignment of subject areas, services provided, types of instruction, and so on.

- A framework for collection evaluation based on format, age, use and other characteristics.

- Performance evaluation for librarians and staff, including frequency, depth, interactivity, rating scale, and areas of assessment.

- Access policies, including patron categories, loan periods, fines, licensing, and use of electronic resources.

- Cataloging and metadata workflows, including division of labor, MARC and non-MARC metadata, use of repositories such as CONTENTdm and Rosetta, et cetera.

The creation of a typology could be used to explore any of these areas (and many others), by posing a question and gathering data to categorize attributes. For example, information on performance evaluation at a group of 50 academic libraries might yield a typology such as:

- Department chair writes a letter of evaluation for librarians once a year.

- Librarian does self-evaluation and meets with department chair to come to agreement on strong and weak points.

- Department chair uses evaluation form with rating scale.

- Some mixture of these processes is used.

The creation of the typology is a qualitative activity that assesses which characteristics are salient (e.g., the use of a rating scale in performance evaluation), as well as lumping or splitting characteristics to create types. It is a lens for analysis that can help make sense of large amounts of data. Creating a typology often uses a kind of componential analysis, first used in research on phonology to describe how sounds are differentiated (e.g., $t$ and $d$ are distinguished by the voicing of the alveolar stop in the case of $d$. Voice is the component that is used to distinguish the two sounds. Trubetskoy, 1969). Componential analysis was adopted in other areas of linguistics and has been used in semantic analysis as well, for example, the difference between the cooking terms fry and bake includes the component oven. Bake is described as +oven, while fry is -oven (Coseriu, 1973; Katz \& Fodor, 1963). 


\section{Semantic Fields and Frames}

Semantic fields are also called lexical fields, and they are groups of related words that might be synonyms from a domain (e.g., cooking), or words related in some other way. They are often used in contrastive linguistics, which compares one or more languages to see how concepts map in different languages. Bolin (1999) compared the semantic field grace in texts from the Bible in their original languages as well as in Latin, English, and German. The words in the field (English words include grace, mercy, kindness, compassion, and pity) did not have a one-to-one correspondence between languages. Semantic fields and frames deal with different types of meaning, which include referential, social, and encyclopedic meaning. Bolin describes these categories of meaning, saying that,

'Referential' meaning is the denotational, dictionary definition of the meaning of a word ... '[s]ocial' or emotive meaning includes ... connotations that include social or class markers, differences in register such as slang, a word's pejorative connotation ... '[e]ncyclopedic' meaning $\ldots$ is all the baggage that any word carries, referential and social meaning, plus the combined weight of all the accumulated meanings, history, and cultural associations that the word carries. $(1999$, p. 8$)$

Semantic frames start with a domain or concept rather than with a group of words. They use the encyclopedic meaning of words and concepts to understand the social, cultural, historical, and any other aspects of meaning of words in a domain. The University of California, Berkeley maintains a site called FrameNet (https://framenet.icsi.berkeley.edu/fndrupal/) that is a collection of semantic frames. An excerpt from the frame accuracy is shown in Figure 1.

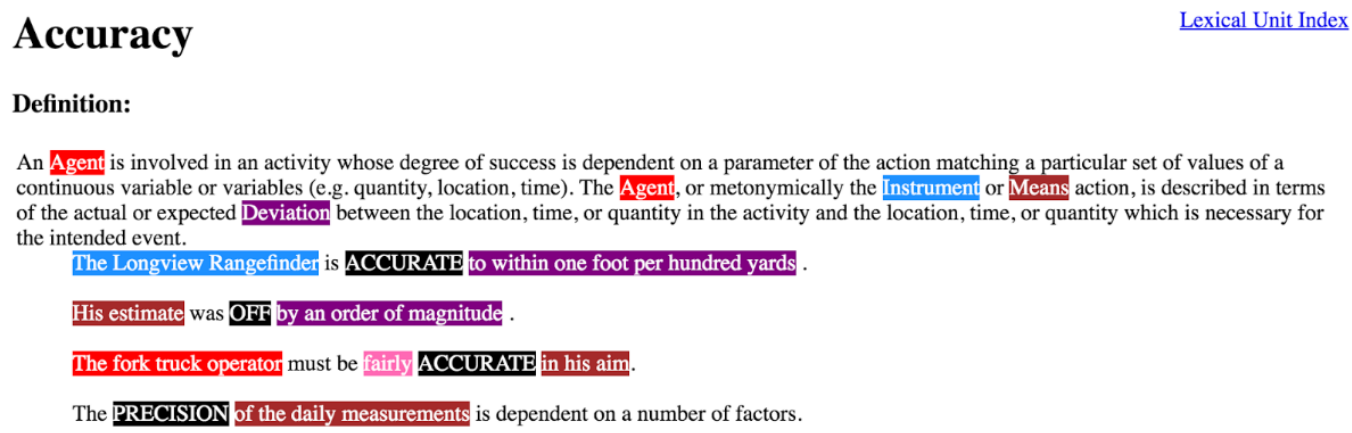

Figure 1. The semantic frame accuracy.

This excerpt shows the referential definition of accuracy, examples of its use, and the social and grammatical participants in the concept. There are many uses for semantic fields and semantic frames in LIS research. Research using semantic fields could include:

- An analysis of the syndetic structure of Library of Congress Subject Headings (LCSH), Library of Congress Classification (LCC), or Dewey 
Decimal Classification (DDC) using a semantic field for a domain, for example, food, war, industry, shelter, music, and so on.

- Semantic field analysis using an aspect of library terminology, for example, format as perceived by librarians and library users.

- Semantic field analysis of library staff and librarian job descriptions, for example, what are the relationships among responsibilities assigned to one or more persons or positions?

- Attributes of information as one or more semantic fields as used in MARC, Dublin Core, and other metadata schemes.

Semantic frames are broader and not as based in lexical items. LIS research could use semantic frames in many ways, for example,

- As with semantic fields, semantic frames could be used to examine areas of LCSH, LCC, and DDC to see how relationships are expressed, and determine how much of the encyclopedic meaning of words and concepts can be expressed in a controlled vocabulary or thesaurus

- Interviews with users could be used to create semantic frames for library services. Examples include instruction, collections, spaces, electronic resources, and so on. Cognitive framing by users may be quite different than the frames used by librarians. Reconciling those frames could improve library services.

- The organizational structure of libraries could be analyzed and reengineered using semantic frames. Exploring frames such as service, employment, education and training, as well as the frames for library services such as cataloging, reference, circulation, and so on, can provide insight and help generate new ideas.

\section{Discourse Analysis}

Discourse is often defined as "language in use" or "language above the level of the sentence," ("Discourse," n.d.), for example, longer texts or utterances that have significant social and cultural meaning. Discourse analysis is used by many fields, sometimes using techniques that may not be considered linguistic analysis. Approaches to discourse analysis that may be useful in LIS including analysis of spoken discourse, for example, a reference interview, which is a communicative event that has meaning in the discourse community of librarians. The need for positive interactions makes it worthwhile to analyze the discourse of events such as these in which librarians and users interact.

Discourse analysis methods include examining the intersection of syntax and semantics, that is, how grammatical forms encode meaning, the study of dialects and registers (language varieties used in social or professional situations, e.g., the language of medicine), critical discourse analysis (Fairclough 1989), which decodes and critiques power relationships, and many others. Conversation analysis, for example, studies the interactions of two or more speakers, including turn-taking, pragmatic meaning, and so on. The analysis of written texts can examine the cohesive devices link parts of a text together. Intertextuality - the relationship of one text with another - is a vital concept in the analysis of both written and spoken discourse (Kristeva, 1984). Both written and spoken discourse can follow scripts, 
patterns, and schema that can be analyzed. (Halliday, 1978; Hoey, 2001; Hodge \& Cress, 1988, 1993; Swales, 1990)

A useful place to start in considering discourse analysis techniques is Halliday's (1978) systemic-functional linguistics (SFL). SFL approaches language by considering its functions; that is, linguistic elements as they are used to create meaning. SFL's system networks, are systems which give choices to speakers. Those choices are determined by social identities and situations. The options and choices create a register, which Halliday calls "a recognizable language variety" (1978, p. 7). Examples include the language of medicine, education, or of a situation such as a reference interview in a library. SFL uses register variables to encode meaning. Field encodes ideational meaning (what a text or discourse is about). Tenor encodes interpersonal meaning (the participants and their roles and status). Mode encodes textual meaning (the devices that link the text together). Situational contexts of language are expressed by registers, and genre is the outermost layer, representing the cultural context and the genres used by a culture. Halliday (1978) describes language as a social semiotic, which is a system of signs that encode meaning. That social setting includes discourse communities (Nystrand 1982), which are professional or other social or cultural groups, who use language to mark themselves as members of their communities.

Halliday deals with genre, but the work of Swales's $(1990,2004)$ on genre analysis is significant. Genre analysis categorizes texts according to their use by certain communities. Other significant work on genre includes Hoey (2001) on the analysis of written texts, Fairclough (1995) who writes on CDA, van Dijk (1995) Lemke (1995b), Yates (1989), Yates and Orlikowski (2002), and Orlikowski and Yates (1994). Lemke, Yates, and Orlikowski have all produced substantial and significant research on the use of genres and discourses in organizations (including any office environment.)

Discourse analysis may draw on the concept of a communicative event (Gumperz and Hymes, 1972). Communicative events (e.g., a job interview, a lecture, religious service) have rules and expectations that are familiar to discourse community members. Discourse analysis pays close attention to the concept of voice, that is, the people and communities implicitly present in a text. Texts with more than one voice represented are called heteroglossic or described as having voices in "heteroglossic opposition." (Bakhtin, 1935). Bolin (2014), states that, "among academic librarians, there are the voices of reference, instruction, and collection development that were identified and discussed by Lemke (1999a) in his analysis of an academic library's re-design of its website." In Lemke's view, "the Reference Orientation voice articulates a discourse formation in which primary positive valuations attach to servicing the user's needs for information" (p. 30). The voice of the reference orientation advocated for a website that would give maximum access to users. In heteroglossic opposition was the instruction orientation voice that advocated the "teach a man to fish" approach, that is, to instruct users in how to find information rather than simply providing the information to them. This illustrates how contrasting voices and opposing discourses can still be based on the same ideology: the idea that librarians should use their expertise to provide services to users. Geertz (1973) introduced the idea of thick description, which examines a culture or community from the inside (as a 
member.) Likewise, Pike (1967) described emic and etic description, an allusion to the phonological concepts phonemic and phonetic. Librarians who do research on the discourse of their own community will produce an emic description, while an outsider would produce an etic one.

Examples of LIS research projects using discourse analysis include:

- Analysis of spoken or other interactive discourse in the library, including in-person, phone, and chat reference.

- Examination of internal communicative events such as evaluation conferences, interviews with job candidates, committee meetings, and so on.

- Research on the various discourse communities among library users including students (who come from different speech communities, socioeconomic levels, and academic fields), faculty (who also vary demographically and have various information needs depending on their area of research), and other library users.

- Analysis of written texts and images such as letters and emails sent to library users, signage, press releases and announcements, and so on.

\section{Genres of Organizational Communication}

Genre analysis may be viewed as an aspect of discourse analysis. All organizations use both spoken and written genres to communicate. They may be unique to one organization or type of organization, but in practice there are genres that are shared by nearly all organizations and certainly by types of organizations. They may include something as generic as the memo, genres associated with employment such as vacancy announcements, letter of offer, contracts, job descriptions, and evaluations, as well as common but more specialized genres such as invoices, budget documents, annual reports, et cetera. Swales (1990, 2004) is a leading scholar on genres, and he describes genre sets and genre chains that are used in organizations, for example, the chain of documents used in hiring: vacancy announcement, letter of application, resume, interview questions, and letter of offer. Genres must meet expectations that are understood by the communities that use the genres. In hiring, for example, an organization judges a letter of application according to whether it meets the genre expectations, in terms of formal writing, appropriate content, and general characteristics of its appearance (e.g., not written on purple paper using Comic Sans). Bolin (2007, 2014, forthcoming 2017) examines genres used in academic libraries, including academic librarian appointment documents (e.g., promotion and tenure standards), academic library websites, and organizational charts. Genre analysis uses the techniques of discourse analysis, including determining authorship, uncovering the voices that are present in the text, the patterns the texts follow, who the participants are, what their relationship is, and how language encodes all these things. Possible research projects using genre analysis include:

- Examining a genre of organizational communication to gain understanding of how the use of that genre affects the library's programs and services, for example, what is being communicated by the library website? 
- Examining internal genres to reveal how employees are being hired, retained, educated, and encouraged, and to see what organizational values are encoded in genres such as performance evaluation.

- Looking at interactions with patrons as a genre and using data such as chat reference transcripts to improve service by understanding how this genre can be used.

- Simmons (2005) discusses the application of genre theory to instruction in information literacy by librarians. She proposes using genre theory to introduce students to the discourse of various disciplines and move toward Critical Information Literacy, a version of Freire's (1970) critical pedagogy.

\section{Existing Studies}

There is already interesting LIS research the uses linguistic approaches, including discourse analysis, various linguistic approaches to semantics, and the examination of documents, conversations, and other texts produced in and by libraries. The following is a selection of recent studies.

Many LIS researchers have used semantic analysis as, including Al-Daihani and Abrahams (2016), who examine the discourse of library use of social media. Zhang, Bhowmick, and Tanaka (2016) look at semantic change in search terms. Hudon, Mas, and Gazo (2005) explore the semantics of ad hoc classification in digital libraries. Tilley and Walter (2016, January) explore the semantics of subject terms. Tsakonas and Papatheodorou (2011) propose semantic enhancement to strengthen the evaluation of digital libraries. Thellefsen, Thellefsen, and Sørensen (2013) explore the mediation of emotion by cognition and the resulting creation of meaning.

Typologies and semantic fields and frames have proven useful for scholars in LIS. Bolin (2007, 2008a, 2008b, forthcoming 2017) created typologies of librarian status and organizational patterns in academic libraries. Fleming-May (2011) creates a typology of library use by examining facets of searching and user behavior. Yang-woo (2014) examines ambiguity in the representation of information needs using a typology of ambiguity. Pomerantz (2005) looks at question taxonomies (e.g., of reference questions) through a linguistic lens. Ofoghi, Yearwood, and Ma (2009) look at the use of semantic frames in information processing. Gruzitis and Dannélls (2017) use University of California, Berkeley's FrameNet as a basis for natural language processing. Boholm (2017) and Colenciuc (2017) are not studies of LIS but are useful for understanding semantic fields. Boholm is a semantic field study that looks at the concept risk in English and Colenciuc uses semantic field theory to examine money in English.

There are many examples of discourse analysis as applied to LIS topics. Bolin (2007, 2014, forthcoming 2017) analyzes the discourse of written texts used in libraries, finding various voices and discourses of service, professionalism, and so on. Forrester, Ramsden, and Reason (1997) look generally at the analysis of conversation and other discourse in libraries. Willett (2016) analyzes the discourse of makerspaces in library literature and social media. Koshik and Okazawa (2012) use conversation analysis to examine chat reference transcripts. Waters (2004) analyzes the discourse of library annual reports. Hicks (2016) examines discourses of advocacy and service and their role in librarian professional identities. Budd 
(2006) proposes discourse analysis to examine communication in LIS. Morris (2010) examines the information science aspect of the interpretation of text. Rabina, Drabinski, and Paradise (2016) use discourse analysis to understand the information needs of people in prison. Hicks (2016) looks the semantics of the concepts library and librarian. Olsson (2016) explores the discourse and semantics of the concept of library users. Oliphant (2015) makes the case for using discourse analysis as a path to social justice research in libraries.

Genre has also been of interest to LIS scholars. Simmons (2005) sees librarians as discourse mediators and advocates the use of genre theory in information literacy instruction. Bolin (2007, 2014, forthcoming 2017) looks at librarian appointment documents, library websites, and library organizational charts as genres with particular uses and expectations. Hinton (2008) looks at the genre characteristics and expectations of a library blog. Nahotko (2016) examines groups of genres in the organization of knowledge, including cataloging and metadata. Skouvig and Andersen (2015) use genre to study the history of information. MacNeil and Douglas (2015) study the evolution of genre in a catalog of archives.

\section{Conclusion}

Librarians come to the profession with a master's degree in library and information science (MLIS) that was preceded by an undergraduate degree that is virtually always in some other field: English, French, history, art history, music, biology, computer science, and so on. Depending on the nature and quality of their undergraduate program, librarians may be informed by the literature and research methods of those disciplines. They may also have other graduate degrees, a second master's or a doctorate in a subject such as education, history, English, or any other discipline that will have provided formative experiences with professional literature and research methods and theoretical frameworks. Any of these can fruitfully inform LIS research and practice. Linguistics, with its focus on discourse, semantics, syntax, anthropology, and sociology, among other things, can be useful in any area of LIS. This article has briefly reviewed some prominent frameworks and methods in linguistic research, along with ideas for applying them to LIS research. These ideas may be more familiar and straightforward to librarians who have a background in linguistics, but there is a large body of interesting literature that is accessible to librarians and scholars who would like to learn more about linguistics and its methods.

\section{References}

Al-Daihani, S. M., \& Abrahams, A. (2016). A text mining analysis of academic libraries' tweets. Journal of Academic Librarianship, 42(2), 135-143. doi:10.1016/j.acalib.2015.12.014

Bakhtin, M. (1935/1981). Discourse and the novel. In Holquist, M. (Ed.), The dialogic imagination. Austin: University of Texas Press.

Boholm, M. (2017). The semantic field of risk. Safety Science, 92205-216. doi:10.1016/j.ssci.2016.10.011 
Bolin, M. K. (1999). Grace: a contrastive analysis of a Biblical semantic field. (Unpublished master's thesis). University of Idaho. Retrieved from http://digitalcommons.unl.edu/libraryscience/6

Bolin, M. K. (2007). A typology and discourse analysis of the status and

appointments of librarians at land grant universities. (Unpublished $\mathrm{PhD}$ dissertation). University of Nebraska. Retrieved from http://digitalcommons.unl.edu/cehsdiss/19/

Bolin, M. K. (2008a). A typology of librarian status at land grant universities. Journal of Academic Librarianship, 34(3).

Bolin, M. K. (2008b). Librarian status at US research universities: Extending the typology. Journal of Academic Librarianship 34(4).

Bolin, M. K. (2014). The language of academic librarianship: The discourse of promotion and tenure. In Williams, D. E., \& Golden, J. (eds.) Advances in library administration and organization, 213-264. Bingley, U.K.: Emerald Group Publishing.

Bolin, M. K. (Forthcoming, 2017). The 21st-century academic library: Global patterns of organization and discourse. Oxford: Chandos.

Budd, J. M. (2006). Discourse analysis and the study of communication in LIS. Library Trends, 55(1), 65-82.

Colenciuc, I. (2016). Functional-semantic field "money" in the English language. Intertext, (3/4), 177-183.

Comrie, B. (1989). Language universals and linguistic typology (2nd ed.). Oxford: Blackwell.

Coseriu, E. (1973). Probleme der strukturellen Semantik: Vorlesung gehalten im Wintersemester 1965/66 an der Universität Tübingen. Autorisierte und bearbeitete Nachschrift von Dieter Kastovsky. Tübingen. Universität Tübingen (Tübinger Beiträge zur Linguistik; 40).

Croft, W. (1990). Typology and universals. Cambridge: Cambridge UP.

Discourse. (n.d.). In Wikipedia, The Free Encyclopedia. Retrieved May 3, 2017, from http://en.wikipedia.org/w/index.php?title=Discourse\&oldid=92987823

Fairclough, N. (1989). Language and power. London: Longman.

Fairclough, N. (1995). Critical discourse analysis: The critical study of language. London: Longman.

Fleming-May, R. A. (2011). What is library use? Facets of concept and a typology of its application in the literature of library and information science. Library Quarterly, 81(3), 297-320.

Forrester, M. A., Ramsden, C., \& Reason, D. (1997). Conversation and discourse analysis in library and information services. Education for Information, 15(4), 283.

Geertz, C. (1973). Description: Toward an interpretive theory of culture. In The Interpretation of Culture. New York: Basic Books.

Greenberg, J. H. (2005). Language universals. Berlin: DeGruyter.

Gruzitis, N., \& Dannélls, D. (2017). A multilingual FrameNet-based grammar and lexicon for controlled natural language. Language Resources \& Evaluation, 51(1), 37-66. doi:10.1007/s10579-015-9321-8

Gumperz, J. J., \& Hymes, D. H. (1972). Directions in sociolinguistics: The ethnography of communication. New York: Holt, Rinehart and Winston. 
Halliday, M. A. K. \& Martin, J. R. (1993). Writing science: Literacy and discursive power. London: The Falmer Press.

Halliday, M. A. K. (1978). Language as social semiotic: The social interpretation of language and meaning. Baltimore: University Park Press.

Hicks, D. (2016). Advocating for librarianship: The discourses of advocacy and service in the professional identities of librarians. Library Trends, 64(3), 615640.

Hicks, D. (2016). Person or place: Rhetorical construction of librarian and library by the information profession community. Canadian Journal of Information \& Library Sciences, 40(4), 318-331.

Hinton, M. J. (2008). Reading the academic library blog through the lens of genre theory: A preliminary discussion. Internet Reference Services Quarterly, 13(4), 347-361. doi:10.1080/10875300802326335

Hodge, R., \& Kress, G. (1988). Social semiotics. London: Polity.

Hodge, R., \& Kress, G. (1993). Language as ideology. London: Routledge.

Hoey, M. (2001). Textual interaction: An introduction to written discourse analysis. London: Routledge.

Hudon, M., Mas, S., \& Gazo, D. (2005). Structure, logic, and semantics in ad hoc classification schemes applied to web-based libraries in the field of education. Canadian Journal of Information \& Library Sciences, 29(3), 265-288.

Katz, J. J., \& Fodor, J. A. (1963). The structure of semantic theory. Language, 39, 170-210.

Koshik, I., \& Okazawa, H. (2012). A conversation analytic study of actual and potential problems in communication in library chat reference interactions. Journal of the American Society for Information Science \& Technology, 63(10), 2006-2019. doi:10.1002/asi.22677

Kristeva, J. (1984). Revolution in poetic language. New York: Columbia University Press.

Lakoff, G. (1986). Women, fire, and dangerous things: What categories reveal about the mind. Chicago: University of Chicago.

Lemke, J. L. (1995b). Textual Politics: Discourse and social dynamics. London: Taylor \& Francis.

MacNeil, H., \& Douglas, J. (2015). Generic evolution and the online archival catalogue. Archives \& Records, 36(2), 107-127. doi:10.1080/23257962.2015.1070094

Morris, J. (2010). Individual differences in the interpretation of text: Implications for information science. Journal of the American Society for Information Science \& Technology, 61(1), 141-149. doi:10.1002/asi.21222

Nahotko, M. (2016). Genre groups in knowledge organization. Cataloging \& Classification Quarterly, 54(8), 553-582. doi:10.1080/01639374.2016.1217576

Nystrand, M. (1982). What writers know: The language, process, and structure of written discourse. New York: Academic.

Ofoghi, B., Yearwood, J., \& Ma, L. (2009). The impact of frame semantic annotation levels, frame-alignment techniques, and fusion methods on factoid answer processing. Journal of the American Society for Information Science \& Technology, 60(2), 247-263. 
Oliphant, T. (2015). Social justice research in library and information sciences: A case for discourse analysis. Library Trends, 64(2), 226-245.

Olsson, M. R. (2016). Re-thinking our concept of users. Australian Academic \& Research Libraries, 47(4), 286-299. doi:10.1080/00048623.2016.1253426

Orlikowski, W J., \& Yates, J. (1994). Genre repertoire: Examining the structuring of communicative practices in organizations. Administrative Science Quarterly, 39: 541-574.

Pike, K. L. (1967). Language in relation to a unified theory of structure of human behavior (2nd ed.). The Hague: Mouton.

Pomerantz, J. (2005). A linguistic analysis of question taxonomies. Journal of the American Society for Information Science \& Technology, 56(7), 715-728. doi:10.1002/asi.20162

Rabina, D., Drabinski, E., \& Paradise, L. (2016). Information needs in prisons and jails: A discourse analytic approach. Libri: International Journal of Libraries \& Information Services, 66(4), 291-302. doi:10.1515/libri-2016-0098

Rosch, E. H. (1973). Natural categories. Cognitive Psychology, 4, 328-350.

Simmons, M. H. (2005). Librarians as disciplinary discourse mediators: Using genre theory to move toward critical information literacy. portal: Libraries and the Academy, 5(3), 297-311.

Skouvig, L., \& Andersen, J. (2015). Understanding information history from a genre-theoretical perspective. Journal of the Association for Information Science \& Technology, 66(10), 2061-2070. doi:10.1002/asi.23313

Swales, J. M. (1990). Genre analysis: English in academic and research settings. Cambridge: Cambridge University Press.

Swales, J. M. (2004). Research genres: Exploration and application. Cambridge: Cambridge University Press.

Thellefsen, T., Thellefsen, M., \& Sørensen, B. (2013). Emotion, information, and cognition, and some possible consequences for library and information science. Journal of the American Society for Information Science \& Technology, 64(8), 1735-1750. doi:10.1002/asi.22858

Tilley, C., \& Walter, S. (2016). What's in a name? College \& Research Libraries, $7(1), 2-6$.

Trubetskoy, N. S. (1969). Principles of Phonology. Translated by Christiane A.M. Baltaxe. Berkeley: University of California Press.

Tsakonas, G., \& Papatheodorou, C. (2011). An ontological representation of the digital library evaluation domain. Journal of the American Society for Information Science \& Technology, 62(8), 1577-1593. doi:10.1002/asi.21559

Van Dijk, T. A. (1995). Discourse semantics and ideology. Discourse \& Society, 6(2), 243-289.

Waters, R. L. (2004). A look at library annual reports. Public Library Quarterly, 23(1), 67-69. doi:10.1300/J118v23n01_10

Willett, R. (2016). Making, makers, and makerspaces: A discourse analysis of professional journal articles and blog posts about makerspaces in public libraries. Library Quarterly, 86(3), 313-329. doi:10.1086/686676

Word order. (n.d.). In Wikipedia, The Free Encyclopedia. Retrieved April 27, 2017, from

https://en.wikipedia.org/w/index.php?title=Word_order\&oldid=776411729 
Yang-woo, K. (2014). Typology of ambiguity on representation of information needs. Reference \& User Services Quarterly, 53(4), 313-325.

Yates, J. (1989). Control through communication: The rise of system in American management. Baltimore: Johns Hopkins University Press.

Yates, J., \& Orlikowski, W J. (2002). Genre systems: Structuring interaction through communicative norms. Journal of Business Communication, 39(1), 13-35.

Zhang, Y., Jatowt, A., Bhowmick, S., \& Tanaka, K. (2016). The past is not a foreign country: Detecting semantically similar terms across time. IEEE Transactions on Knowledge \& Data Engineering 28(10), 2793-2807. 